\title{
Prostheticity, Disability, and Spaceflight
}

\section{Martin Boucher}

\author{
Correspondance: mx6_boucher@laurentian.ca
}

Martin Boucher is a PhD Candidate in Human Studies at Laurentian University. His work is primarily situated in disability studies and posthumanism, but he maintains an interest in the philosophy of social science and the history of ideas. He also works in, and coordinates research on, peer support and community mental health.

Acknowledgements: The author would like to acknowledge the two anonymous reviewers for their thoughtful comments. He would also like to thank the editor, Caitlin Heppner, for her attention to detail and thoughtful revision of this work. The paper has been made much clearer and stronger thanks to their efforts.

\begin{abstract}
In this short work, the author will reflect on how we might understand the technologysubject relationship in a way that equally captures the position of the individual with a disability and that of the interplanetary astronaut. The works of Tamar Sharon in mediated posthumanism and Dan Goodley in critical disability studies will be consulted. This cursory exploration will conclude that both the astronaut and the individual with a disability are congruent posthuman subjects insofar as their relationship to technology challenges the idea of a transhumanist overcoming of human limits. Exploring this relationship can tell us something about how posthuman subjects may be understood more generally.
\end{abstract}

Keywords: Critical Disability Studies, Mediated Posthumanism, Mediation, Reflexivity, Originary Prostheticity, Tamar Sharon, Dan Goodley, Rosi Braidotti

Posthumanist theory is beginning to make a considerable impact on the theoretical foundations of Critical Disability Studies. To a certain extent there has been engagement with cyborg theory in this field for over a decade; ${ }^{1}$ however, more recently, work influenced by Rosi Braidotti's The Posthuman has been gaining momentum. ${ }^{2}$ Given that the goal of this issue of Con Texte is to provide short reflections on posthuman topics, I will not summarize or explore these literatures in great detail. Instead, I will reflect on a question that came to me recently while watching the launch of Falcon Heavy, and will do it from the perspective of this latter stream of posthumanism in disability studies. The question I asked myself was: within the eventual goal—spearheaded by SpaceX and its CEO Elon Musk - of colonizing Mars, how do we interpret the astronaut from a posthuman critical disability perspective? What can we learn from disability about this futurist superhuman event and vice versa?

It seems to be the consensus in the space technology field that future Mars astronauts (or colonists) are already born. As I write this, the Austrian Space Forum (OeWF) is conducting an isolated Mars analogue mission on the Arabian Peninsula (Austrian Space Forum). At least for

\footnotetext{
${ }^{1}$ See for e.g. Quinlan and Bates 2014; Kafer 2013; Reeve 2012; Goodley 2011; Moser 2000, 2005.

${ }^{2}$ See for e.g. Roets and Braidotti, 2012; Goodley 2014; Goodley et al. 2014; Goodley and Runswick-Cole 2016; Goodley et al. 2018.
} 
optimists, interplanetary travel is crossing from science fiction to science proper. Of the plethora of questions this raises, I will limit myself quite narrowly to a reflection on how we might modify our framework of understanding to capture the interaction with technology from both the perspective of the individual with a disability and that of the interplanetary astronaut.

In a sense, this paper has nothing to do with space travel. It is interested in the way we interpret the protagonist of such an adventure. For the transhumanist, technological advancement has endowed the human with the means to surpass himself towards a new and unrecognizable future-epitomized in the cosmo-colonist. The question of disability seems to be at the other extreme of the spectrum. Technology is not enhancement but correction towards the normal range of human limitations. In both cases, the difference is contingent on the acceptance of a foundational humanness with concrete limits. Critical posthumanism and critical posthuman disability studies challenges this foundation. As result, I will conclude that both the astronaut and the individual with a disability are congruent posthuman subjects insofar as a) their differentiation is contingent on a shaky natural-able human category, and b) they share the same originary and reflexive relationship with technology. Exploring this relationship can tell us something about how posthuman subjects may be understood more generally. However, within the limits of this special issue, this paper can only point us in the direction of a complete analysis. I will therefore focus primarily on a few works by Tamar Sharon and Dan Goodley and on the narrow questions of the congruency of the subjects mentioned above and the model of technology that can make sense of this relationship. However, it is important to recognize that exhausting the question posed here would require a much more detailed engagement with the work of these two authors among others.

\section{What is an Astronaut?}

One undeniable fact is that the astronaut's survival and success is contingent on their relationship to a whole array of highly sophisticated technological machinery. Furthermore, the interplanetary astronaut depends on a large network of support staff, training infrastructure, political and social human investment, and tremendous economic wealth in order to eventually carry out their mission. The complex technological and human networks that exist to support one individual, on an International Space Station (ISS) spacewalk for example, lead us to think of these individuals as somehow surpassing the natural limits of the human animal. It is this idea of surpassing itself (i.e. going beyond nature) and the what that we are surpassing (i.e. natural human limits) that is at issue. The paradigm of critical posthumanism recognizes that (a) there is no fixed natural 'human' and so no natural limits to be surpassed, (b) all beings are interconnected and depend on networks of human, non-human, and inorganic entities - they are never stand alone agents, and (c) the novelty of survival in space, for example, is not a change in kind from other achievements, but a continued expression of the possibilities of life. This does give rise to new subjectivities, but not contradictory ones. Outside of such a posthumanism, the 'disabled body' is interpreted as the antithesis of the highly techno-enhanced interplanetary astronaut. They are both new and protean posthuman subjects, but one does not represent the overcoming of the other.

The prevailing idea of the natural human and its fixed limits and abilities has been intrinsically challenged from the critical disability perspective, because that subject- the individual with a disability_-was not considered truly 'human' to begin with. This population has been subject to dehumanization through a collection of historical events such as freak shows, institutionalization, 
segregation in education, medical experimentations etc., because they represent the 'other' of the able-human and embody a problem to be solved. Prosthetics, surgical/pharmaceutical treatments, rehabilitation programs, service animals, social support workers, and community organizations are examples of technologies and networks that allows individuals living with a disability to attain the theoretical 'natural ability' of the human being. Although Critical Disability Studies challenges this latter idea of natural ability, it remains the prevailing interpretation outside of it. Alternatively, "disability has always demanded to be recognized not as lack but possibility"; moreover, we should "be careful not to be seduced by shiny technology when, on a more mundane level, we are already potentially enhancing our humanity through a myriad of inter-relationships" (Goodley, Lawthom, and Runswick-Cole 352). A critical understanding means a re-evaluation of how we interpret those technologies and relationships mentioned above.

We want to avoid a simplistic interpretation where individuals with disabilities are seen as lacking something and must be brought back to some kind of normalcy, and where the astronaut is someone who attained this normalcy and becomes exceptional by surpassing him or herself while leaving normalcy in their wake. From the perspective of lack (or suffering), the cold world of ableism is as frigid as the emptiness of space, and technology allows for the overcoming of these limiting factors. Alternatively, a positive view of disability sees these new ways of being as transgressing those limits with transformative results. We consider neither as lacking or exceptional - they are both typical posthuman subjects. Critical Posthumanism centres on the productive ambiguity that we 'do not yet know what bodies can do.' ${ }^{3}$ Technology and new ways of interacting with each other lead to an expansion of possibilities and a substantive change in how people experience and relate to the world. This is equally true for the individual living with a disability and the astronaut depending on complex equipment to survive in space.

Generally speaking, these insights emerge out of what Tamar Sharon calls Radical Posthumanism. Though there are many models of posthumanism, we will be relying on Sharon's analysis here because it will allow us - within the parameters of this short work-to discuss three important orienting concepts: reflexivity, mediation, and prostheticity.

\section{Posthumanism's Axes}

Sharon's goal in proposing a new model of posthumanism is to synthesize two non-humanist posthumanisms; namely, the methodological and radical models. It is her contention that these two forms are compatible and have insights about technology that are useful for a more complete understanding. Before I get into these insights, I will mention some of the dimensions she uses in her taxonomy (Sharon 17-56) to distinguish the different models and why it may be useful for our purposes. She organizes her taxonomy on three axes; I will look at them one at a time.

On the first axis, Sharon identifies pessimism on one end and optimism on the other. On the pessimistic end of the spectrum we see models of dystopic posthumanism-those that see technology in a negative or dangerous light — and on the other end, those posthumanisms that are optimistic about technology or try to find affirmative ways to use and develop new technologies. These posthumanisms are not yet differentiated on the question of why technologies may be

\footnotetext{
${ }^{3}$ This is a reference to Spinoza interpreted by Deleuze and often used by Braidotti and other posthuman thinkers. I identify it as productive here, but it has been criticized elsewhere for being an empty or sliding reference with little connection to its source (see Abrams 89-94).
} 
liberating, but they all share this optimism. A posthumanism that has a positive and affirmative view of technology would be welcome in Disability Studies because technology has been historically problematic (and continues to be so) because it is mostly corrective. As suggested by Goodley, "Disabled people's relationships with technology are not always desired, chosen nor productive" (Goodley 152), but on the other hand, technologies can be integrated in affirmative and desired ways. A balance ought to be struck between affirming new possibilities and proliferating old oppressive practices and norms. At that point the relationship is no longer affirmative, but disciplinary and limiting (an expression of potestas). Through its embodiment of living the body differently, "dis/ability promotes a conversation with technology, cyborgs and just as importantly (though perhaps not as marketable) extended senses of self and competence. Technology enhances humanity - not simply in the ways lauded by the transhumanists-but also on the level of the everyday" (Goodley 107).

The typical image of the Mars colonist is in the realm of sci-fi fantasy and transhumanist futures. It is the image of an enhanced, super-human body that renders other beings inadequate/lacking, and represents an event that casts our historical present in a primitive light. This is the very perspective that is damaging for disability, but the problems with it are not as apparent for the astronaut because their relationship to technology has not been historically problematic - it has been central. The problem with integrating them into the same framework is that their humanness has not been challenged in the same way, so technology can be seen as pure enhancement or unfettered hubris. There is no apparent need to complicate this relationship, making it easy to descend into an uncritical liberal optimism or equally uncritical dystopian pessimism. Whether influenced by the excitement of technological novelty or by historical caution and fear, both the astronaut and the person with disabilities ought to have a common ground on which to judge the affirmative possibilities of technology. A suitable critical perspective should be able to account for both cases.

On the second axis is historical-materialism and philosophical-ontological thought. The only posthumanism identified as ontological-philosophical is radical posthumanism. This perspective does not deny the historical-material condition that gives rise to the posthuman or its historicomaterial contingency; however, its rethinking of the historical relationship between technology, the material world, and the interacting subjects necessitates a new ontology. Radical posthumanism is influenced by the so called "ontological turn" which we can describe as resistance to the humanist ontology that gives a privileged place to the 'human' in relation to all other 'things.' This traditional ontology cannot capture the relationships between life as a vital force, living matter, the material world, and the emergence of contingent and fluid subjectivities (Braidotti, "Posthuman Critical Theory," 22ff). The critical perspectives that are emerging from recent thought about disability are "almost emblematic of the posthuman predicament" because they do not only criticize the old humanist order of things, but also represent "the advocacy of new, creative models of embodiment" (Braidotti 146). As interplanetary spaceflight and colonization becomes a possibility, we should equally examine the astronaut in light of the new embodiments it represents. And we should do this as a challenge to the established modernist ontology and not as a simple historical development from, or overcoming of, its central figure: the human.

This brings us to the final axis: humanist vs non-humanist posthumanisms. Though 
methodological posthumanism does not directly or radically challenge ontology, it shares antihumanist roots and interprets the world of objects/technology in a way that is consistent with radical posthumanism. Both see beings as relational subjects that are constituted and emerge within (and never outside) the networks that surround them. For Sharon, their non-humanist foundation is the most important aspect differentiating these approaches from all other contemporary posthumanisms. It also opens the possibility of a synthesis between methodological and radical posthumanisms discussed above. I will not explore how she makes the synthesis here, but I will discuss two major insights she has gained by working it through; namely, reflexivity and mediation.

\section{Reflexivity, Mediation and Prostheticity}

The term reflexivity has a rich history in sociology and social studies. In its many iterations, it usually denotes a circular relationship between two or more things, where neither is the definitive cause and the other the effect. In terms of Sharon's discussion of radical posthumanism, reflexivity exists between technology and the context within which it emerges (including ourselves). Technology itself is not following a fatalistic sprint towards destruction or liberation; conversely, if we do play a role we do not get to choose whether or not we are affected or changed by technology. Technology and society, technologies and subjects, prostheses and persons are always intertwined.

This differentiates it on many planes, as Sharon reminds us "technology is both substantive and non-essentialist, constitutive and non-deterministic. A reflexive understanding of technology allows for its emergence from within social, political, and economic contexts and maintains that our technologies shape our engagement with the world" (Sharon 89). In liberal posthumanism, technology is simply instrumental. It has use-value and we control it by force of will as we would with any other object in the world. This relationship is supported by traditional modernist philosophies that separate the subject from the world of objects - the inside from the outside. On the other hand, dystopic posthumanisms have a substantive view of technology. They imbue technology with some kind of inherent value (usually negative) or alternatively some independent self-propulsion that usually challenges the essential characteristics or values of the human (e.g. dignity or autonomy). In mediated posthumanism our relationship is a bit more complex. As she put it, "The reflexive view shares traits with both instrumentalism and substantivism: it agrees with instrumentalism that technology is in some sense controllable, and it agrees with substantivism that technology is value-laden" (Sharon 89); however, it differentiates itself because it does not believe that technologies have essential destructive or liberating properties, and the social and political values that technologies embody are not inherent and predetermined-both of these can always be shaped and 'negotiated'. The idea that technology is imbricated or in a reflexive relationship with the posthuman accepts that it radically changes the nature of our existence, but that it is not deterministic because we reshape and change its ends as we navigate the novelty it introduces. As mentioned in the previous section, this is an essential step for disability studies to begin to form some affirmative perspective on technology that is able to resist either the transhumanist or liberal posthumanist type relationship (which sees disability or typical-ability as a problem for which technology is the solution), and the dystopic posthumanism type (which draws a strict and negative distinction between prosthetic-normalizing technologies and enhancement-violation dichotomy).

The concept of mediation easily follows reflexivity and tries to explain its various relational mechanisms. Sharon uses Bruno Latour and Don Ihde's work to explore this. To summarize what is 
a complex and useful argument, technology mediates (in specific ways) the experience between person and world. Ihde for example identifies four types of relationships that are mediated by technology: embodiment, hermeneutic, alterity, and background relations.

Embodiment relations represent the technological means of access or contact with the world. This includes traditional prosthetics and other technologies that metaphorically 'place themselves in between' the person and its world, such as artificial limbs, hearing devices, and life support systems. Hermeneutic relations are those in which the world is somehow translated or represented for interpretation as in medical testing/imaging, battery health indicators, and audible pedestrian signals. Alterity relations are those where individuals interact with the technologies themselves such as in robotics and artificial intelligence, and in the research and development of new technologies. Lastly, background relations constitute relations that are so integrated in our everyday experience that we are no longer conscious of them. That is, until they break down and we need to reestablish a different relationship to them. Examples of the latter would be adequate sidewalks and streets, lifts and ramps, lights, and Internet access. For the astronaut, these relations are sometimes different, but are all present. For both subjects, these four types of relations represent a different form of mediation between person-technology-world.

Mediation provides us with a practical means with which to explore the role of technology as they are encountered in the world. What is especially relevant here are embodiment relations and background relations as individuals with disabilities are most often aware of how technologies can be experienced in these relations. As Goodley et al. put it, "the tied togetherness between the guide dog and human; or personal assistant and employer, demands us to think again about old humanist notions of agency, responsibility and subjectivity" (352). Additionally, background relations become conscious only when they break down. In the marginal experience of individuals with disabilities, this happens more often than those whose ways of navigating the world has become the standard (e.g. no adequate curb, inaccessible classroom/building/organization/business, inaccessible information/instructions/expectations in various settings etc.). The astronaut's experience is limiting in different ways, but these two types of relations remain important: for example, in the extension of one's body through the spacesuit (i.e. embodiment) and in the essential systems that constantly go from background (in normal conditions) to foreground (when they need to be maintained or monitored) as they support and maintain life in space.

Finally, I will present one more concept to explain where our relationship with technology comes from, and why it might support a posthuman understanding. Originary prostheticity is the idea that technology is not external and additive in relation to the human, but rather it considers "the body and self as already including prostheses as an integral part of its organization” (Sharon 98). Sharon recounts the work of Bernard Stiegler who argued that prosthesis is not an extension of the body, but rather constitutes the body as a human body. This contrasts with the supplemental view of prosthesis where technology is to be used for some purpose or is to be resisted or promoted for its effect on the human (Sharon 98-101). The supplemental view assumes that something remains untouched and unpenetrated by technology: a human nature or core substance. Rather, originary prostheticity claims that there is no such essential human nature on which technology acts and that, moreover, the co-constitution of the human and technology throughout history has made it impossible to isolate one from the other. At the very core of ourselves is a "mutual imbrication"- to 
use Braidotti's words (qtd. in Sharon 101)_of technology and self. Originary prostheticity offers a more accurate representation of the nature of technology and prosthesis in the network-process of posthuman embodiment. Both in the case of the astronaut and the individual with a disability, we colloquially see their devices as additive. The space suit allows the individual, untouched by the void of space, to walk on unknown worlds - but it is still one giant leap for man. In the case of the individual with a disability, unhampered by their inadequate body, the white cane allows the individual to navigate the world. In both cases, we are using a supplemental view. We ought to recognize that the astronaut's suit is not an expensive jacket, but one aspect of the network that constitutes the astronaut as a different (and complete) posthuman subject, which is equally true of the white cane.

\section{Conclusion, the Disabled Astronaut}

The astronaut does not represent the overcoming of the limitations of human life on earth, its support systems are not a means to overcome the limitations of the human body, and the interplanetary event is not a fatalist result of human techno-history and evolution-they represent the tendency of life to extend towards affirmative possibilities, and technology's ever-present role in this process. Nothing that existed before has been surpassed or overcome; only the limits that we thought were natural or technically unfathomable have been shown not to be so. The exclusively positive value placed on the astronaut (and the relatively negative one placed on the 'disabled body') is destabilized by the disappearance of the natural-able body reference category. For the liberal and dystopic posthumanisms, these two embodied selves - the individual living with a disability and the inter-planetary astronaut-represent two incongruent human extremes. What I have proposed is that a more critical perspective - using reflexivity, mediation, and originary prostheticity — brings them together as two congruent posthumans. It would benefit Critical Disability Studies and critical posthumanism to further develop such a model of technology-person relations. Lastly, though I have focused here on a model of congruency for these two subjects, I would suggest-following Goodley's distinction between Critical Disability Studies and critical ableist studies ${ }^{4}$ - that their mirroring relationship to technology still necessitates different forms of engagement with things like social history, policy, and economics (among others). I did not explore this question here.

${ }^{4}$ See chapter 2 of Goodley's Dis/ ability Theory, 2014. 


\section{Works Cited}

Abrams, Thomas. "Braidotti, Spinoza and Disability Studies After the Human." History of the Human Sciences, vol. 30, no. 5, 2017, pp. 86-103.

Austrian Space Forum. “AMADEE-18 Mars Simulation Press Release.” oewf.org, 2017, www.eananet.eu/Documents/A18_AO_May2017_V2RELEASE.pdf

Braidotti, Rosi. “Cyberfeminism with a Difference.” University of Utrecht Women's Studies, 1996. www.let.uu.nl/womens_studies/rosi/cyberfem.htm.

. "Posthuman Critical Theory." Critical Posthumanism and Planetary Futures. Edited by Debashish Banerji and Makarand Paranjape. Springer, 2016, pp. 13-32.

—. The Posthuman, Polity Press: Cambridge, 2013.

Goodley, Dan. “Developments: Critical Disability Studies.” Disability Studies and Interdisciplinary Introduction. Sage, 2011, pp. 157-175.

_. Dis/ability Theory: Theorising Disablism and Ableism. Routledge, 2014.

Goodley, Dan, Rebecca Lawthom, and Katherine Runswick-Cole. "Posthuman Disability Studies." Subjectivity, vol. 7, no. 4, 2014, pp. 342-361.

Goodley, Dan, Kirsty Liddiard, and Katherine Runswick-Cole. "Feeling disability: theories of affect and critical disability studies.” Disability \& Society, vol. 33, no. 2, 2018, pp.197-217.

Goodley, Dan and Katherine Runswick-Cole. "Becoming Dishuman: Thinking about the Human Through Dis/ability.” Discourse: Studies in the Cultural Politics of Education, vol. 37, no. 1, 2016, pp. 1-15.

Kafer, Alison. “The Cyborg and the Crip.” Feminist, Queer, Crip. Indiana UP, 2013, pp. 103-128.

Moser, Ingunn. "Against Normalisation: Subverting Norms of Ability and Disability." Science as Culture, vol. 9, no. 2, 2000, pp. 201-240.

—. "On Becoming Disabled and Articulating Alternatives: The Multiple Modes of Ordering Disability and their Interferences." Cultural Studies, vol. 19, no. 6, 2005, pp. 667-700.

Quinlan, Margaret M. and Benjamin R. Bates. "Unsmoothing the Cyborg: Technology and the Body in Integrated Dance.” Disability Studies Quarterly, vol. 34, no. 4, 2014, no pag.

Reeve, Donna, "Cyborgs, Cripples and iCrip: Reflections on the Contribution of Haraway to Disability Studies." Disability and Social Theory. Edited by Dan Goodley, Bill Hughes, and Leonard Davis. Palgrave Macmillan, 2012, pp. 91-111.

Roets, Griets and Rosi Braidotti. "Nomadology and Subjectivity: Deleuze, Guattari and Critical Disability Studies." Disability and Social Theory. Edited by Dan Goodley, Bill Hughes, and Leonard Davis. Palgrave Macmillan, 2012, pp. 161-178.

Sharon, Tamar. Human Nature in an Age of Biotechnology: The Case for Mediated Posthumanism. Springer, 2014. 